\title{
A HIGH-ASPECT-RATIO DESIGN FOR THE INTERNATIONAL THERMONUCLEAR ENGINEERING REACTOR
}

\author{
JOHN C. WESLEY and the U. S. ITER HOME TEAM ${ }^{a}$ \\ General Atomics \\ P. O. Box 85608 \\ San Diego, CA 92168-9784 \\ (619)-455-2686
}

\begin{abstract}
Design features and performance parameters for HARD - the high-aspect-ratio $(A=4)$ International Thermonuclear Engineering Reactor (ITER) design variant developed by the U. S. ITER Team - are presented. The HARD design makes it possible for ITER to achieve both the ignition/extended-burn and the steady-state/technologytesting performance goals set forth in the ITER Terms of Reference. These performance capabilities are obtained in a device that is otherwise similar in concept, size and cost to the low-aspect-ratio $(A=2.8)$ ITER design defined during the ITER Conceptual Design Activity (CDA). HARD is based on the same physics and engineering guidelines as the $\mathrm{CDA}$ design and achieves the same ignition performance (ignition margin evaluated against ITER-89P confinement scaling) with inductively-driven plasmas as ITER CDA, but with much greater margin for inductive sustainment of the pulse duration. With non-inductive current drive, HARD operates at lower plasma current and higher plasma density and bootstrap current fraction than ITER CDA, is less constrained by beta limit and divertor considerations, and has increased peaking of the neutron wall load at the test module location. These factors give HARD a much better potential than ITER CDA to achieve the steady-state operation and $1 \mathrm{MWa} / \mathrm{m}^{2}$ technology-testing fluence goals of the ITER objectives.
\end{abstract}

\section{INTRODUCTION}

The Programmatic Objectives set forth in the ITER Terms of Reference ${ }^{1}$ encompass three major requirements: 1) achievement of ignition and extended ( $t_{\text {bum }} \geq \sim 200 \mathrm{~s}$ ) fusion burn, with steady-state as an ultimate goal, 2) an integrated demonstration of the technologies essential for a fusion reactor, and 3) operation to perform integrated testing of the high-heat-flux and nuclear components required for future fusion reactors. The third objective is challenging, since it requires that ITER operate with high reliability and availability $(\geq 10 \%)$ for extended periods to achieve a testmodule fluence of $1 \mathrm{MWa} / \mathrm{m}^{2}$. This fluence is a minimum

- See \$XI for contributors and affiliations requirement: ITER is to be designed to allow the more reactor-relevant test-module fluence of $3 \mathrm{MWa} / \mathrm{m}^{2}$ to be achieved if sufficiently favorable plasma and device operational conditions can be obtained.

The rationale for HARD (High Aspect Ratio Design), the ITER concept developed by the U. S. ITER Team as an alternate to the low-aspect-ratio ITER design ${ }^{2,3}$ developed by the ITER participants during the CDA lies in the third Programmatic Objective. The combination of lower plasma current, increased bootstrap current fraction and higher onaxis toroidal field inherent in a high-aspect-ratio design gives HARD much greater potential than ITER CDA for achieving the $1 \mathrm{MWa} / \mathrm{m}^{2}$ minimum fluence goal set by the third objective, and of proceeding on to the $3 \mathrm{MWa} / \mathrm{m}^{2}$ limit. HARD obtains this enhanced capability primarily by the relaxation of the operational constraints ${ }^{4}$ imposed by the plasma beta limit and divertor power handling and erosion limitations. ${ }^{5}$ This technology-testing performance gain is obtained without compromising ignition performance relative to ITER CDA, and without undue increase in physics or engineering risk or device size and cost.

\section{DESIGN AND PERFORMANCE OVERVIEW}

The HARD design modifies only the aspect ratio, and is intentionally based on the same physics and engineering guidelines ${ }^{4}$ set for the ITER CDA design. HARD employs the same general device layout and double-null plasma configuration and the same $\mathrm{Nb}_{3} \mathrm{Sn}$ superconducting magnet technology ${ }^{6}$ as ITER CDA. The HARD design also retains the same nuclear shielding concept and build ${ }^{5}$ and magnet construction and design allowables as ITER CDA: known deficiencies of the CDA design are duplicated in order not to obscure the effects of the change in aspect ratio.

The design features of HARD can best be understood by comparison with those of ITER CDA. The CDA design has an aspect ratio, $A=2.79$, an on-axis toroidal magnetic field, $\mathrm{B}=4.85 \mathrm{~T}$ and a plasma current, $\mathrm{I}=22 \mathrm{MA}$ for operation with an ignited plasma. In contrast, HARD employs higher aspect ratio, $A=4.0$, higher toroidal field, $\mathrm{B}=7.11 \mathrm{~T}$, and lower plasma current, $\mathrm{I}=14.8 \mathrm{MA}$ for ignition operation. The two designs are compared in Fig. 1. 


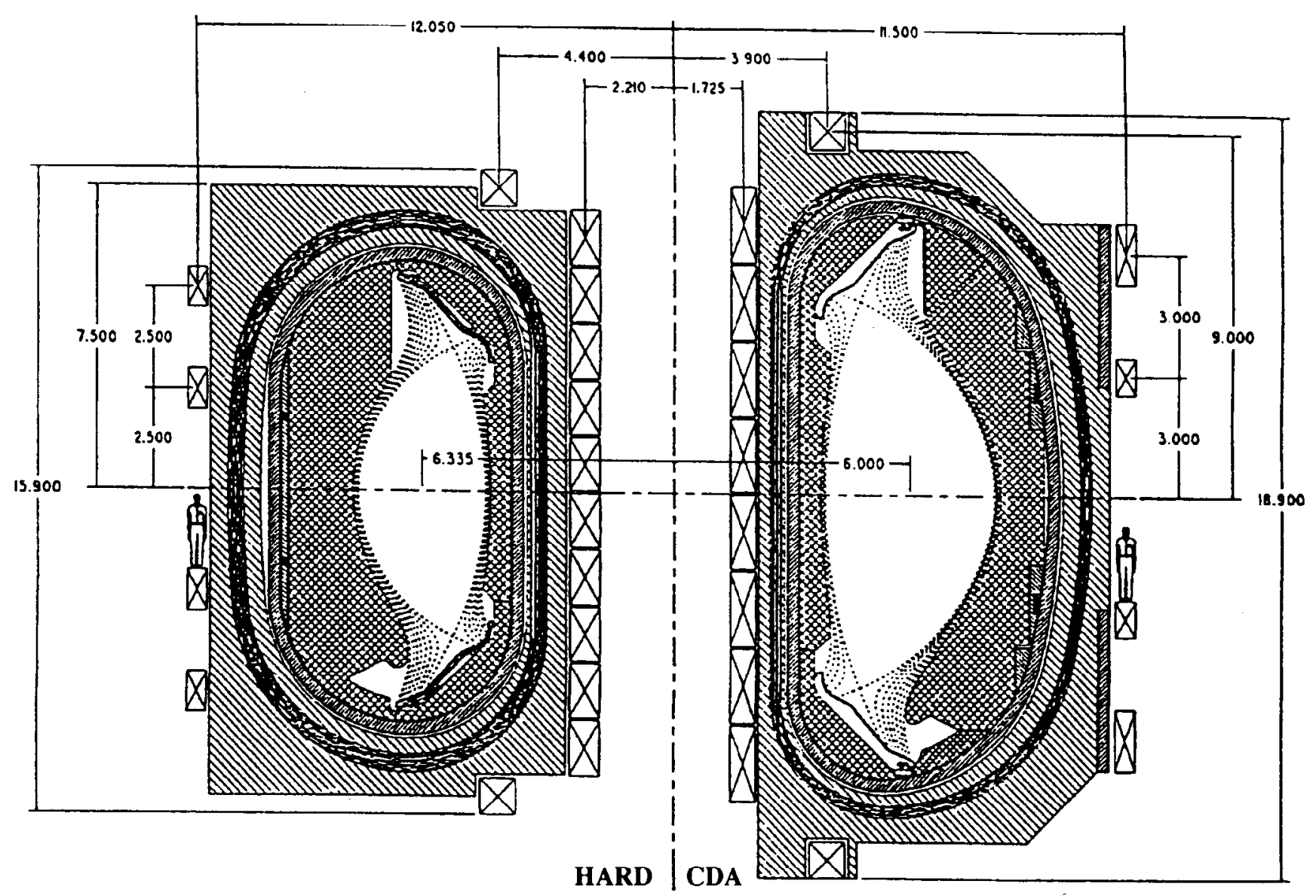

Fig. 1. Cross-sections of HARD and CDA ITER designs. Dimensions in meters

While the two designs are very similar in general concept and configuration, HARD trades plasma minor radius and current for higher toroidal magnetic field, and importantly, a larger-radius central solenoid with an additional $130 \mathrm{~V}$-s of flux-swing capability. HARD also provides the capability to operate at higher plasma density with non-inductive current drive. The larger solenoid gives HARD a robust long-pulse capability with inductive drive, and the higher plasma density facilitates operation for technology testing in either a steady-state mode, with the plasma current fully sustained by a combination of noninductive current drive and bootstrap current, or in a very-long-pulse hybrid mode, in which $30 \%$ of the plasma current is sustained by non-inductive current drive, with the balance of the current sustained by bootstrap current and inductive drive. $^{7}$

The increased toroidal field for HARD is obtained using the same $\mathrm{Nb}_{3} \mathrm{Sn}$ cable-in-conduit superconductor technology as ITER CDA. The higher on-axis field capability accrues partially from the effect of the higher aspect ratio, which reduces the peak field, $\mathrm{B}_{\mathrm{TF}}(\mathrm{max})$, at the conductor relative to the on-axis field, and partially from an increase in $\mathrm{B}_{\mathrm{TF}}(\max )$ to $13.3 \mathrm{~T}$ (as compared to $11.4 \mathrm{~T}$ for ITER CDA). While the peak field is higher, the HARD toroidal field (TF) magnets operate at lower current density and meet the same current-density/field, protection and structural guidelines specified for the CDA TF magnets. ${ }^{5}$

The parameters and performance of HARD and ITER CDA for inductively-driven ignition operation ${ }^{7}$ are compared in Table I. The HARD parameters provide the same ignition performance (ignition margin evaluated against ITER-89P confinement scaling, see $\$ \mathrm{~V}$ below) as ITER CDA.

\section{TABLE I}

ITER Designs Compared:

Device Parameters and Ignition Performance

\begin{tabular}{llll}
\hline Parameter & Units & CDA & HARD \\
\hline $\mathrm{A}$ & - & 2.79 & 4.00 \\
$\mathrm{R}$ & $\mathrm{m}$ & 6.00 & 6.33 \\
$\mathrm{~B}$ & $\mathrm{~T}$ & 4.85 & 7.11 \\
$\mathrm{~B}_{\mathrm{TF}}(\max )$ & $\mathrm{T}$ & 11.4 & 13.3 \\
$\mathrm{I}$ & $\mathrm{MA}$ & 22 & 14.8 \\
$\mathrm{P}_{\text {fus }}$ & $\mathrm{MW}$ & 1080 & 850 \\
$\Delta \Psi_{\mathrm{PF}}{ }^{*}$ & $\mathrm{~V}-\mathrm{s}$ & 331 & 464 \\
$\mathrm{t}_{\text {bum }}$ & $\mathrm{s}$ & 240 & 2060 \\
\hline
\end{tabular}

* Total poloidal field system flux swing 
The testing performance aspects of the two designs are compared in Tables II and III. The performance of HARD is superior to that of CDA in both the steady-state (full noninductive drive) and hybrid (extended pulse operation with partial non-inductive drive) modes. This superiority follows direculy from the higher bootstrap current fraction $\left(f_{b s}\right)$ and lower total plasma current of HARD.

In the steady-state mode (Table II), these factors reduce the non-inductive current drive requirement for HARD to 5.3 MA, as compared to 11.5 MA for CDA. Because of the requirement, for the same current drive pouer $\left(\mathrm{P}_{C D}\right), \mathrm{HARD}$ can operate with higher plasma density $\left(<n_{e}>\right)$ and higher fusion power $\left(P_{\text {fus }}\right)$ than CDA. The higher plasma density allows HARD to maintain acceptable peak divertor heat loads $\left(\mathrm{Q}_{\text {div }}\right)$ and peak plasma temperature $\left(T_{\text {e.div }}\right)$ while operating with more than three times the tesi-module wall loading $\left(\Gamma_{n, \text { lesi }}\right)$. HARD achieves both higher fusion $Q$ and higher wall loading and thus provides both more reactor-relevant wall test conditions. The test duration $\left(t_{\text {ops }}\right)$ required to achieve the ITER testing fluence goal of $1 \mathrm{MWa} / \mathrm{m}^{2}$ decreases dramatically, and the prospects for achieving a $3 \mathrm{MWa} / \mathrm{m}^{2}$ testing fluence goal in HARD are much more credible than those for CDA.

\section{TABLE II}

ITER Designs Compared: Steady-State Mode $\left(\mathrm{I}_{\text {ind }}=0\right)$

\begin{tabular}{llll}
\hline Parameter & Units & CDA & HARD \\
\hline $\mathrm{P}_{\mathrm{CD}}$ & $\mathrm{MW}$ & 113 & 113 \\
$\mathrm{I}$ & $\mathrm{MA}$ & 14.6 & 11.1 \\
$\mathrm{P}_{\text {fus }}$ & $\mathrm{MW}$ & 420 & 960 \\
$\mathrm{Q}$ & - & 3.7 & 8.5 \\
$\mathrm{f}_{\mathrm{bs}}$ & - & 0.28 & 0.52 \\
$<\mathrm{n}_{\mathrm{e}}>$ & $10^{20} \mathrm{~m}^{-3}$ & 0.64 & 1.12 \\
$\mathrm{~T}_{\mathrm{e}}$,div & $\mathrm{eV}$ & 65 & 65 \\
$\mathrm{Q}_{\text {div }}{ }^{*}$ & $\mathrm{MW} / \mathrm{m}^{2}$ & 5.2 & 6.4 \\
$\Gamma_{\text {n, lest }}$ & $\mathrm{MW} / \mathrm{m}^{2}$ & 0.57 & 1.98 \\
$\mathrm{t}_{\text {ops }}\left(1 \mathrm{MWa} / \mathrm{m}^{2}\right)^{* *}$ Years & 8.8. & 2.5 \\
\hline
\end{tabular}

* "Physics" heat loads and temperatures, w/o peaking factors

** Calendar time, with $25 \%$ availability and $20 \%$ attenuation by test module first-wall

Similar performance gains accrue for HARD in the hybrid mode, where a design requirement that $30 \%$ of the current be sustained by non-inductive means $\left(\mathrm{f}_{\mathrm{CD}}=0.30\right)$ is imposed to provide current profile control during very-longpulse operation. Here, because of increased bootstrap fraction and lower total current, only 3.9 MA of inductively-driven current $\left(\mathrm{I}_{\text {ind }}\right)$ is required for HARD, as compared to $9.2 \mathrm{MA}$ for CDA. This reduction in inductive drive requirement combined with the greater inductive drive (V-s) capability of the HARD central solenoid results in a eight-fold increase in hybrid pulse length, and a corresponding reduction in the number of pulse required. In particular, HARD is able to reach the $1 \mathrm{MWa} / \mathrm{m}^{2}$ testmodule fluence goal with less than 1,000 pulses. Divertor conditions (plasma temperature and peak power loading) are also more favorable than for CDA.

\section{TABLE III}

ITER Designs Compared: Hybrid Performance $\left(f_{C D}=0.30\right.$ )

\begin{tabular}{|c|c|c|c|}
\hline Parameter & Units & CDA & HARD \\
\hline $\mathrm{P}_{\mathrm{CD}}$ & $\mathrm{MW}$ & 113 & 113 \\
\hline & MA & 15.6 & 10.2 \\
\hline $\mathrm{I}_{\text {ind }}$ & MA & 9.2 & 3.9 \\
\hline$f_{\text {ind }} / f_{b s}$ & - & $0.59 / 0.11$ & $0.38 / 0.32$ \\
\hline$P_{\text {fus }}$ & MW & 1090 & 1080 \\
\hline$\left\langle\mathrm{n}_{e}\right\rangle$ & $10^{20} \mathrm{~m}^{-3}$ & 1.13 & 1.50 \\
\hline$T_{e, d i v}^{*}$ & $\mathrm{eV}$ & 11 & 17 \\
\hline $\mathrm{Q}_{\text {div }}{ }^{*}$ & $\mathrm{MW} / \mathrm{m}^{2}$ & 5.0 & 2.5 \\
\hline$\Gamma_{\mathrm{n}, \text { test }}{ }^{* *}$ & $\mathrm{MW} / \mathrm{m}^{2}$ & 1.46 & 2.20 \\
\hline $\begin{array}{l}t_{\text {bum }} \\
\text { Pulses for:** }\end{array}$ & s & 3,100 & 22,000 \\
\hline$\ldots 1 \mathrm{MWa} / \mathrm{m}^{2}$ & - & 8,500 & 800 \\
\hline$\ldots 3 \mathrm{MWa} / \mathrm{m}^{2}$ & $=$ & 26,000 & 2,400 \\
\hline
\end{tabular}

HARD also has the potential for achieving greater reliability and availability than ITER CDA. The reduced number of pulses necessary for testing operation reduces concern about the effects of cyclic thermal loading on the fatigue lifetime and reliability of the divertor and first wall and blanket/shield systems, and about loss of availability associated with frequent change-out of these systems. The prospects that HARD offers for steady-state or very-longpulse hybrid operation also hold the potential that HARD can achieve greater reliability and availability owing to a reduction in the number of plasma disruptions. While the relationship between disruption probability and pulse duration in true- or quasi-steady-state operation remains as an important issue for future physics $R \& D$, the expectation is that fewer operational cycles will result in an overall reduction in the number of disruptions encountered, with corresponding improvement in reliability and availability.

\section{SELECTION OF THE HARD DESIGN POINT}

The choice of the HARD design point is based on a systematic study of ITER performance and design optimization by means of the I-A-B ${ }_{\text {TF }}$ systems analysis methodology ${ }^{7}$ developed during the ITER CDA. The method allows the complex relationship among ITER plasma and nuclear performance, plasma confinement and other physics limitations and device size, field and aspect ratio to be clearly understood. Briefly stated, the kernel of the method is that once the key variables of plasma current (I), aspect ratio $(A)$ and maximum field $\left(B_{T F}\right)$ at the TF coil winding are specified, and if the plasma safety factor, radial build between the plasma edge and inboard TF coil 
winding, and plasma elongation are also specified, then at each point in $\left(\mathrm{I}, \mathrm{A}, \mathrm{B}_{\mathrm{TF}}\right)$ space the size and other geometrical attributes (e.g., cost) of the resulting tokamak are uniquely determined. Furthermore, if neutron wall loading is specified together with the ITER physics specifications, ${ }^{5}$ then each machine also has unique plasma performance parameters for inductive-driven ignited operation. The analysis clearly shows that equal ignition performance (confinement multiplier $\mathrm{H}=2$ relative to ITER 89-P scaling) can be obtained at various combinations of $I, A$ and $B_{T F}$, but that the resulting machines exhibit major differences in other performance attributes such as inductive burn duration and technology testing performance.

Assessment of technology testing performance can be included in the $\left\{\mathrm{I}, \mathrm{A}, \mathrm{B}_{\mathrm{TF}}\right\}$ analysis, but optimization of performance at each point in I-A-B ${ }_{\mathrm{TF}}$ space is more complex because the number of performance variables now exceeds the number of constraint equations and an optimization figure of merit is needed. Key results of evaluating the technology testing performance of the CDA design and selecting a design point for HARD are:

CDA Performance: The maximum average neutron wall loading attainable under steady-state, current-driven operation is limited by divertor power handling and is $0.27 \mathrm{MW} / \mathrm{m}^{2}$ with an unseeded plasma and $0.42 \mathrm{MW} / \mathrm{m}^{2}$ if impurity seeding (the addition of $\sim 0.1 \% \mathrm{Fe}$ ) is invoked to ameliorate divertor heat loads. Under hybrid operation, the CDA design can achieve a wall load $0.40 \mathrm{MW} / \mathrm{m}^{2}$ and burn time of $1380 \mathrm{~s}$; if impurity seeding is permitted these increase to $\sim 1 \mathrm{MW} / \mathrm{m}^{2}$ and $\sim 3100 \mathrm{~s}$.

Constraints on CDA Steady-State Performance: The maximum neutron wall loading attainable for ITER CDA is 0.2-0.4 MW/ $\mathrm{m}^{2}$ under constraints of confinement, beta and divertor heat loads. Although the divertor heat load is the most severe constraint on steady-state operation, even if this constraint is removed, the beta and confinement constraints prevent ITER CDA from attaining the minimum average wall loading goal of $\sim 0.8 \mathrm{MW} / \mathrm{m}^{2}$ set during the CDA for technology testing under steady-state operation.

HARD Design Point Selection: The HARD design point is selected to maintain the same ignition performance as ITER CDA while better optimizing steady-state and hybrid performance. For steady-state operation, neutron wall load is maximized; for hybrid operation the neutron fluence (wall load $\mathrm{x}$ burn time) is maximized. Optimization is done by adjusting the operational parameters $(n, T, I, \ldots)$ subject to the same confinement, beta, divertor power loading and current-drive power constraints set for the respective CDA operational mode. ${ }^{7}$ By moving from the CDA design point $\left(I=22 \mathrm{MA}, \mathrm{A}=2.79, \mathrm{~B}_{\mathrm{TF}}-11 \mathrm{~T}\right)$ to the HARD design point $\left(I=15 \mathrm{MA}, \mathrm{A}=4, \mathrm{~B}_{\mathrm{TF}}-13 \mathrm{~T}\right)$, neutron wall loading for steady-state operation at acceptable divertor conditions increases to $\geq 1 \mathrm{MW} / \mathrm{m}^{2}$. Burn time for hybrid operation increases to $22,000 \mathrm{~s}$ at a wall load of $\sim 1.27 \mathrm{MW} / \mathrm{m}^{2}$. The attainable per-pulse fluence from hybrid operation increases by a factor of $\sim 8$ relative to CDA.

\section{HARD DESIGN OBJECTIVES AND GUIDELINES}

The objective of the HARD design study was to develop a conceptual design for the $15 \mathrm{MA}, \mathrm{A}=4$ design point identified by the systems studied described above. Because of limited time and resources, the design could not be developed in as much detail as the CDA design, and the focus of the HARD study was on those aspects of the design that were known to change significantly at higher aspect ratio and/or present obvious problems. At the same time, the intent of the study was to obtain a one-on-one comparison with the CDA design, so the HARD study employs the same physics and technology basis as the CDA design, and HARD design intentionally does not rectify certain of the deficiencies (e.g., inadequate nuclear shielding thickness) known to exist in the CDA design. Such deficiencies, which mandate a $5-10 \%$ increase in the CDA major radius, will also have a similar effect on a final HARD design point. However, one of the major CDA deficiencies, the lack of $\mathrm{V}$-s contingency for adverse plasma resistive loss during start-up or burn is already accommodated in HARD: the robust burn V-s capability of HARD eliminates the need for any additional growth in major radius to provide more $\mathrm{V}$-s.

HARD is generally based on the same physics design guidelines as ITER CDA. The same ITER 1989-P confinement scaling, confinement margins (H-factor), edge safety factor, plasma impurity model and operational limits - maximum beta and plasma density - are used. The only significant differences are in the allowable TF ripple, $0.5 \%$ peak-to-peak at the outer plasma boundary, rather than $1.5 \%$ for $\mathrm{CDA}$, and internal inductivity range, $0.65 \leq l_{\mathrm{i}}(3) \leq 1.0$ rather than the range $0.55 \leq l_{i}(3) \leq 0.75$ set for CDA. The reduced ripple follows from considerations of permissible $\alpha$-particle ripple loss at higher aspect ratio; the higher range of inductivity follows from considerations of optimal MHD stability at high beta.

The same considerations of axisymmetric equilibrium and operational flexibility - the ability to accommodate variations in plasma internal inductivity $l_{i}(3)$ and pressure $\beta_{p}-$ specified $^{8}$ for CDA are also retained for HARD, and plasma elongation, specified in terms of $\mathrm{k}_{95}$, the elongation at $95 \%$ poloidal flux, is held at 2.0 . However, axisymmetric stability of the HARD plasma is evaluated using an MHDbased non-rigid displacement model, ${ }^{9}$ rather that the rigid-displacement "wire-array" model ${ }^{8}$ used for CDA. The non-rigid model is necessary because the plasma displacements in either device have appreciable non-rigid components, and the growth rate and stability margin evaluations obtained for either device with the wire-array model are have appreciable inaccuracies.

The same device configuration and assembly maintenance concept as CDA are retained for HARD. Plasma-to-first-wall clearance and divcrtor channel geometry are the same as CDA, with the exception that the outboard divertor channel length in HARD is the full $1.5 \mathrm{~m}$ specified for CDA, rather than the $1.4 \mathrm{~m}$ that resulted in the 
final CDA layout. Structural and magnet materials are identical to those for CDA, and key engineering allowables - magnet design parameters and structural design guidelines $^{6}$ - are also the same as for CDA. The HARD TF design does employ a different magnet winding pack composition - with a modified superconductor/ stabilizer/steel/helium ratio - to achieve higher magnetic field within the CDA magnet design guidelines. Poloidal field (PF) magnet design and allowables are essentially identical to those for CDA.

HARD is evaluated against the same safety and environmental guidelines ${ }^{10}$ as $\mathrm{CDA}$, and the same CDAdefined costing algorithms are used to assess HARD costs.

\section{PHYSICS AND DESIGN INTEGRATION ISSUES}

The HARD design is based upon the same physics guidelines $^{5}$ set for the CDA design. These guidelines simple algorithms specifying confinement scaling models, ignition margin requirements, plasma profile parameters and plasma operational limits (beta, density, radiation power balance and axisymmetric stability, etc.) - were derived from data and analysis compiled by the CDA Team and employed to set the overall CDA design point, establish design requirements for the various tokamak and ancillary systems, and determine the performance capabilities of the CDA device.

The CDA guidelines are directly applicable to a low-A $(A-3)$ configuration. For the HARD design, physics analysis was conducted to quantify the effect of higher $A$ and to, where necessary, modify to the guidelines for an A 4 design. Significant considerations and differences relative to the CDA guidelines include:

1) Confinement Scaling Model: The ITER 89-P power law scaling for L-mode energy confinement ${ }^{5}$

$$
\tau_{\mathrm{E}}^{\text {ITER89-P }}=0.048 \mathrm{I}^{0.85} \mathrm{R}^{1.2} \mathrm{a}^{0.3} \mathrm{k}_{\mathrm{x}}^{0.5} \mathrm{n}_{20} 0.1 \mathrm{~B}^{0.2} \mathrm{~A}_{\mathrm{i}}^{0.5} \mathrm{P}^{-0.5}
$$

is retained as the basis for evaluating HARD performance. Here $k_{x}$ is the elongation at the separatrix, $A_{i}$ is the atomic mass, $\mathrm{n}_{20}$ is the line-average density in units of $10^{20} \mathrm{~m}^{-3}$ and $P$ is the total power. Written in terms of $n \tau_{E} T$, the $89-P$ scaling results in a favorable $A$ dependence, with $n \tau_{E} T$ $\left(\mathrm{IA}^{1.13} / \mathrm{R}^{0.35}\right)^{2.3}$. The A-dependence of the 89-P scaling is supported by the results of explicit aspect ratio variation experiments in JT-60 and TFTR. Favorable $n \tau_{E} T$ scalings also apply for the ITER-89 OL (Offset-Linear) and 90-H (H-mode) scalings. Application of ITER 89-P scaling and the requirement to obtain ignition at an $\mathrm{H}$-mode multiplier of 2 results in a HARD device with an overall size (radius to the outer PF coils) and volume very similar to CDA.

2) MHD Stability at High Beta: A comprehensive MHD stability analysis based on nearly 9000 PEST code cases was conducted for $2 \leq A \leq 6$ and a wide range of plasma current and pressure profiles and central and edge $q$ values. This study showed that the Troyon beta-limit coefficient $g_{\text {troyon }}$ is independent of aspect ratio over the range of 2.5-5 that is applicable to ITER designs. The study did show that the range of current profiles for optimal MHD stability, as qualified in terms of the dimensionless intemal plasma inductance parameter $l_{\mathrm{i}}(3)$, does shift to higher $l_{\mathrm{i}}(3)$, with optimal stability at $A=4$ being obtained for $0.65 \leq l_{\mathrm{i}}(3) \leq 0.85$, as opposed to $0.55 \leq l_{\mathrm{i}}(3) \leq 0.75$ for $\mathrm{A}=3$. For $\mathrm{HARD}$, the CDA guideline of $\mathrm{g}_{\text {troyon }}=2.5 / 3.0$ is retained, with the more conservative limit of 2.5 applying for inductively-driven ignition, and the less conservative limit of 3 for steady-state and hybrid operation, where the non-inductive current drive is expected to provide more control over the current density profile.

3) Heating and Current Drive: Studies with the ACCOME current drive code demonstrate that the same 1.3 MeV neutral beam system ${ }^{11}$ designed for ITER CDA can provide efficient current drive for HARD. A nominal power of $113 \mathrm{MW}$ is required: this power is obtained with 12 CDA beamlines, arranged in groups of 3 modules on four tangential injection ports (Fig. 2). Two of the three modules are aimed inboard of the plasma center, at a tangency radius of $5.0 \mathrm{~m}$, the third module is aimed slightly inboard of the plasma center, at $\mathrm{R}=5.96 \mathrm{~m}$. The triplet beamline configuration matches the beam deposition profile to the smaller HARD plasma and facilitates injection access through the HARD tangential ports, which have $0.6 \mathrm{~m}$ less vertical height than their CDA counterparts.

The ACCOME studies show that the HARD neutral beam system alone is capable of generating (in combination with the bootstrap current) a nearly optimal current density profile with $l_{\mathrm{i}}(3) \cong 0.74$. Supplementing the beam driven current with lower hybrid (LH) current drive in HARD is neither required or desirable, since LH drives current only in the outer portion of the plasma and would result in a toobroad of a current profile. Elimination of LHCD frees up an access port for the fourth neutral beam triplet (the CDA design uses a 3-module/3-port neutral beam configuration) and also eliminates LH launcher R\&D.

An alternate current drive scenario with $100 \mathrm{MW}$ of ion-cyclotron fast-wave (FW) current drive supplemented with $40 \mathrm{MW}$ of LHCD has also been shown to be feasible for HARD. Such a system would require 7 access ports: two shared by FW and LH launchers, and 5 with FW launchers. Comparison of alternate FW+LH scenarios for HARD with their counterparts for CDA shows that the alternate scenarios are more favorable for HARD than for CDA owing to the higher plasma densities in HARD.

HARD, like CDA, uses approximately $25 \mathrm{MW}$ of electron cyclotron (EC) heating and/or current drive for plasma initiation assist and current profile/disruption control. The higher toroidal field in HARD requires an increase in gyrotron frequency to $175 \mathrm{GHz}$. Current profile control studies have demonstrated that $25 \mathrm{MW}$ of EC power launched at an angle of $17^{\circ}<\phi<23^{\circ}$ can modify the current density in HARD sufficiently to suppress tearing modes at the $q=2$ surface. Application of the same 


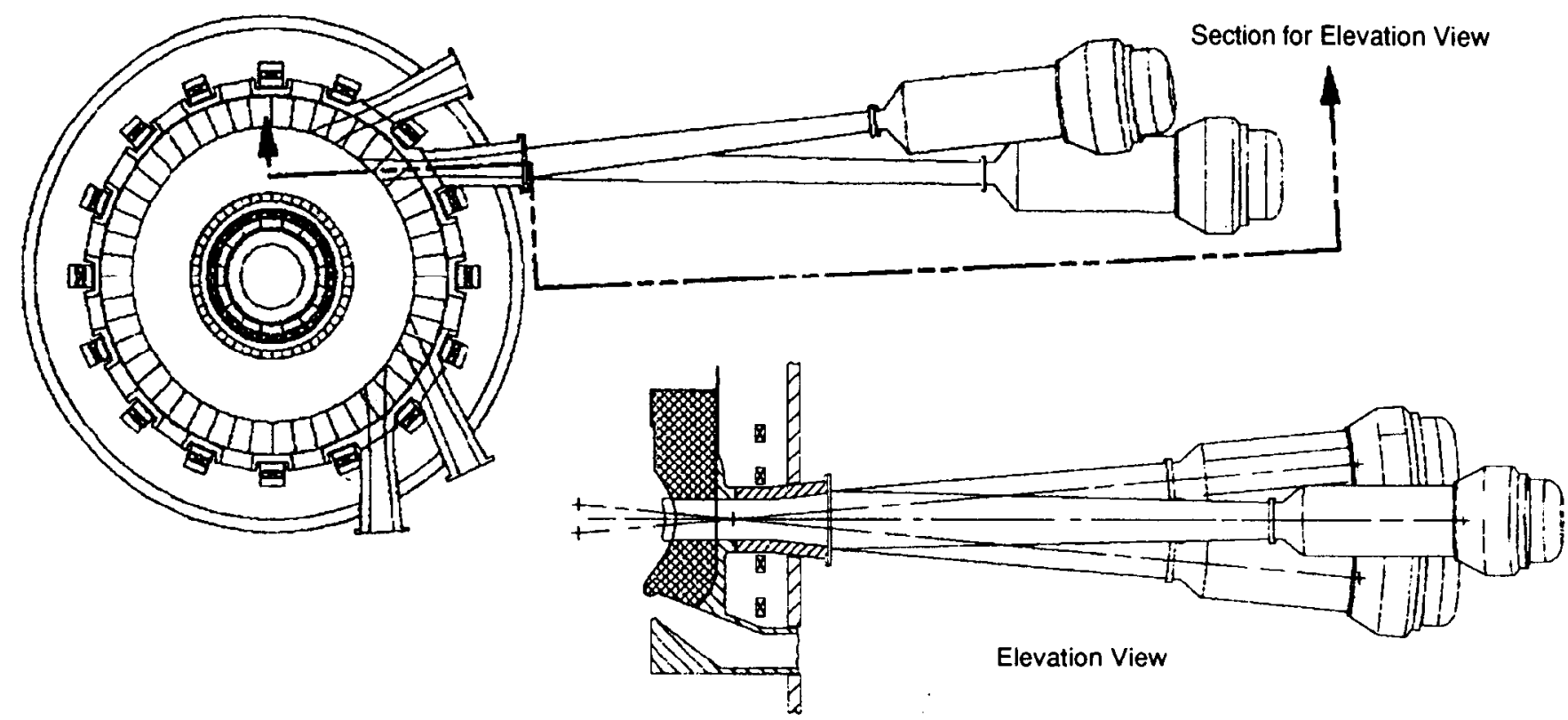

Fig. 2. HARD neutral beam system plan and elevation views. Twelve beamlines are installed on the four ports shown

technique for CDA is less effective owing to an unfortunate lack of EC current drive efficiency for CDA parameters.

4) Ripple Losses and Toroidal Field Ripple Specification: The lower plasma current and higher aspect ratio of HARD result in increased $\alpha$-particle ripple losses for a given ripple. The concern here is primarily with the localized power loading that the escaping $\alpha$ 's provide on the first wall between TF coils. The allowable ripple in HARD is set to $0.5 \%$ (peak-to-average), a factor of three lower than for CDA. The lower ripple specification requires moving the position of the outboard leg of the HARD TF coil $0.55 \mathrm{~m}$ out in major radius relative to the position of the CDA TF outer leg. The resulting impact on TF stored energy and outboard PF coil efficacy is small, and the outer leg modification also facilitates the tangential access required for the neutral beam injection system.

5) PF Equilibrium and Axisymmetric Stability: The smaller plasma minor radius and higher aspect ratio of HARD raise concern that the PF equilibrium and stability requirements are more challenging than those for ITER CDA. HARD uses the same general PF coil configuration as ITER CDA, with 8 (rather than 7) pairs of up-down symmetric PF coil pairs (see Fig. 1). For HARD, the central solenoid is subdivided into $5(\mathrm{x} 2)$ rather than 4 (x2) equal coil pairs: the additional division provides a better match to the HARD plasma height and allows the PF system to accommodate changes and uncertainties in the plasma profile parameters $\left(l_{i}\right.$ and $\left.\beta_{\mathrm{p}}\right)$ without undue increase in magnetic energy. Studies of the HARD PF capabilities show that the coil system allows operation over the full range of profile parameters needed for all three operational modes (ignition, steady-state and hybrid), with only very minor restrictions at high $\beta_{p}(>\sim 2)$. Overall operational flexibility is identical to that achieved in CDA. The total ampere turns in the outer PF coils increase somewhat relative to those of the CDA PF system, but the overall PF stored energy with even worst-case profile conditions remains acceptable: $16 \mathrm{GJ}$ at end-of-burn for HARD versus $14.8 \mathrm{GJ}$ for CDA.

The HARD design employs the same type of "twinloop" passive stabilization system ${ }^{8}$ as is provided in CDA for control of axisymmetric modes. Here consideration of the effects of non-rigid displacements is required to obtain an accurate evaluation of the stability characteristics of HARD and ITER CDA. In both cases, the plasma displacements without the constraint of rigid displacement (as was assumed for the "rigid-wire" stability analysis conducted during the $\mathrm{CDA}^{8}$ ) are more strongly localized near the X-point and the small-R side of the plasma ${ }^{9}$. The flux perturbation from such displacements is not well coupled to the outboard-only stabilizing loops of the CDA design, and an evaluation of the stability properties of the original CDA design shows that growth rate for axisymmetric instabilities is unacceptably high ${ }^{9}$, especially for plasmas with a combination of low $\beta_{p}$ and low $l_{\mathrm{i}}$.

The addition of an inboard set of twin loops rectifies the problem in both the CDA and HARD designs and provides adequate passive stabilization in both designs over their respective plasma profile operational range. Instability growth rates in HARD are about twice those for CDA $\left(24 \mathrm{~s}^{-1}\right.$ for CDA versus $55 \mathrm{~s}^{-1}$ for HARD). Peak control power doubles, but the same power control technology planned for $\mathrm{CDA}$ is adequate.

6) Disruption Effects. HARD has significantly more favorable characteristics overall than CDA with regard to the electromagnetic and thermal effects of plasma disruptions. Worst-case magnetic pressures on the HARD first wall following a fast current quench are about $20 \%$ less than the corresponding pressure in CDA. Shear loading 
pressures on the vertical sides of the in-vessel modules in HARD are the same as for CDA for the inboard modules, and about $60 \%$ higher than for CDA on the outboard modules. Thermal energy loading from the thermal quench phase of the disruption is about $9 \mathrm{MJ} / \mathrm{m}^{2}$ for HARD as compared to $12 \mathrm{MJ} / \mathrm{m}^{2}$ for CDA.

7) Divertor Conditions and He Exhaust Performance. The HARD design provides a full $1.5-\mathrm{m}$ distance between the plasma $X$-point and the outer divertor target strikepoint. This increase relative to CDA (where nuclear shielding layout considerations limited the distance to $1.4 \mathrm{~m}$ ) and the higher plasma densities inherent in HARD operation result in improvement in divertor conditions for both ignited and steady-state operation. For ignited operation, where the wall loading is held fixed, the improvement is manifested in lower divertor plasma temperature and heat load Table IV. For steady-state operation, where the allowable wall loading is constrained by peak divertor plasma temperature (and to a lesser degree by peak power loading), HARD can operate at three times the average wall loading of CDA. While $66 \mathrm{eV}$ is still higher than desired (a specification of $\leq 30 \mathrm{eV}$ was set during the CDA to allow a safety factor for toroidal peaking and modeling uncertainties), HARD requires only a modest degree of improvement in plasma boundary conditions to obtain both acceptable wall loading and satisfactory divertor conditions for steady-state operation.

The heat loads in Table IV result from calculations with the Braams B2 divertor modeling code and do not include the physics and engineering "safety factors" that must be applied to the modeling results to given the peak static heat loads to be accommodated by the divertor target. The CDA-recommended safety factors are 3.4 for "physics" effects (to allow for known omissions from the B2 code, uncertainties in the modeling parameters, and toroidal peaking from locked MHD modes) and 1.5 for "engineering" effects (to allow for target misalignment and contour errors and the effects of toroidal field ripple). ${ }^{5}$ The combined peaking factor is 5.1 , so a B2 heat load of $4.8 \mathrm{MW} / \mathrm{m}^{2}$ corresponds to a design heat load of $25 \mathrm{MW} / \mathrm{m}^{2}$. When the thermal-averaging effect of separatrix sweeping is taken into account, the effective design heat load is approximately $12 \mathrm{MW} / \mathrm{m}^{2}$, which is close to the power loading limit of practical target designs.

\section{TABLE IV}

Comparison of HARD and CDA Divertor Modeling*

\begin{tabular}{|c|c|c|c|c|c|c|}
\hline \multirow[t]{2}{*}{ Design } & \multicolumn{3}{|c|}{ Ignition } & \multicolumn{3}{|c|}{ Steady-State } \\
\hline & $\Gamma_{n}$ & $\mathrm{~T}_{\text {div }}$ & $Q_{\text {div }}$ & $\Gamma_{n}$ & $\mathrm{~T}_{\text {div }}$ & $\mathrm{Q}_{\text {div }}$ \\
\hline $\mathrm{CDA}$ & 1.0 & 34 & 5.6 & 0.39 & 66 & 5.2 \\
\hline HARD & 1.0 & 21 & 4.1 & 1.13 & 66 & 6.4 \\
\hline
\end{tabular}

*From $B 2$ code, $T_{\text {div }}=$ divertor electron temperature, in $\mathrm{eV}$; $\Gamma_{\mathrm{n}}=$ torus-average first-wall neutron loading, in $\mathrm{MW} / \mathrm{m}^{2}$;

$\mathrm{Q}_{\text {div }}=$ peak divertor target heat flux, in $\mathrm{MW} / \mathrm{m}^{2} . \mathrm{T}_{\text {div }}$ and

$Q_{\text {div }}$ without physics and engineering peaking factors
The engineering peaking factor (EPF) that enters into setting the design heat load is higher for HARD than for CDA, primarily because of the higher toroidal field, which reduces the divertor target field incidence angle to $1.2^{\circ}$ for HARD, rather than $1.4^{\circ}$ for CDA. This increases the EPF for HARD to 1.58 , resulting in a $6 \%$ additional increase in design heat loads for HARD relative to those for CDA. This correction is for the ignition case. The correction for steadystate is $11 \%$. Applying this incremental correction raises the equivalent $B 2$ heat load for HARD steady-state to $7.1 \mathrm{MW} / \mathrm{m}^{2}$, as compared to $5.2 \mathrm{MW} / \mathrm{m}^{2}$ for CDA.

Neutral particle modeling studies show that the HARD divertor geometry is adequate to provide effective helium exhaust despite a $25 \%$ reduction in the poloidal height of the pumping duct throat.

8) Neutron Wall Load Peaking. Peaking of neutron wall loading at the outboard midplane where the test modules are located is higher for HARD than for CDA: the torus-average to test-module-average peaking factor is 1.75 for HARD versus 1.46 for CDA. The increased peaking factor arises primarily from the increased Shafranov shift inherent in operation at higher aspect ratio. The higher testmodule peaking factor combined with a higher allowable average wall loading results in a 3.5-x increase in testmodule wall loading for HARD relative to $\mathrm{CDA}$ $\left(1.98 \mathrm{MW} / \mathrm{m}^{2}\right.$ versus $\left.0.57 \mathrm{MW} / \mathrm{m}^{2}\right)$.

\section{ENGINEERING DESIGN AND FACILITY}

An evaluation of key engineering and facility requirement considerations for HARD shows that there is no substantial increase in engineering difficulty or facility requirements associated with an increase in aspect ratio and magnetic field strength. The toroidal field and poloidal field magnet designs and $\mathrm{Nb}_{3} \mathrm{Sn}$ conductor technology invoked for the CDA design are adequate for HARD, and the assembly/maintenance concepts developed for CDA apply equally well for HARD, albeit with concern for either design about the small clearances available. HARD also fits easily within the CDA facility.

Major conclusions from the HARD study about engineering design features and facility requirements for HARD are:

1) Toroidal and Poloidal Magnet Systems. The higher toroidal magnetic field needed for HARD can be obtained using the same magnet design and $\mathrm{Nb}_{3} \mathrm{Sn}$ cable-in-conduit superconductor proposed ${ }^{6}$ for ITER CDA. The HARD TF coils have their section-average current density $(<j>)$ and winding-pack current density $\left(\left\langle j_{\text {pack }}\right\rangle\right)$ reduced consistent with operation at higher field. Use of ternary alloy (Nb-Ti$\mathrm{Sn}$ ) superconducior rather than binary alloy optimizes magnet performance, and provides adequate temperature and energy margins ( $\Delta \mathrm{T}_{\text {slab }}$ and $\Delta \mathrm{U}_{\text {stab }}$, respectively) at a 13.4 T peak field. Key parameters of the HARD and CDA TF magnets are compared in Table V. 
TABLE V

Comparison of HARD and CDA TF Magnet Parameters

\begin{tabular}{lll}
\hline Parameter (Units) & HARD & CDA \\
\hline Conductor Current $(\mathrm{kA})$ & 47 & 38 \\
$\mathrm{~B}_{\max }(\mathrm{T})$ & 13.4 & 11.2 \\
$<\mathrm{j}>\left(\mathrm{A} / \mathrm{mm}^{2}\right)$ & 11.1 & 13.4 \\
$<\mathrm{j}_{\text {pack }}>\left(\mathrm{A} / \mathrm{mm}^{2}\right)$ & 29.1 & 35.1 \\
$\Delta \mathrm{T}_{\text {stab }}(\mathrm{K})$ & 3.4 & 3.4 \\
$\Delta \mathrm{U}_{\text {stab }}\left(\mathrm{mJ} / \mathrm{cm}^{3}\right)$ & 900 & 900 \\
Dump voltage $(\mathrm{kV})$ & 20 & 20 \\
\hline
\end{tabular}

The HARD TF magnet design meets the structural criteria set for the CDA TF magnets. Peak stresses for the nominal end-of-burn loading condition are comfortably within allowables (Table VI).

The HARD PF coil design concept is identical to that of the CDA PF system. The $13.3 \mathrm{~T}$ peak field at the PF conductor is identical for HARD and CDA.

\section{TABLE VI}

HARD TF Coil Stress Analysis

\begin{tabular}{|c|c|c|c|}
\hline Component & Location & Stress $(\mathrm{MPa})$ & Allowable(MPa) \\
\hline $\begin{array}{l}\text { Conductor } \\
\text { conduit }\end{array}$ & $\begin{array}{l}\text { 1st turn, } \\
\text { inboard leg }\end{array}$ & 510 (Tresca) & 800 (Tresca) \\
\hline Coil case & $\begin{array}{l}\text { Shear panel } \\
\text { attachment, } \\
\text { outboard leg }\end{array}$ & 630 (Tresca) & 800 (Tresca) \\
\hline $\begin{array}{l}\text { Conductor } \\
\text { insulation }\end{array}$ & $\begin{array}{l}\text { Upper inboard } \\
\text { leg }\end{array}$ & 20 (shear) & 33 (shear) \\
\hline $\begin{array}{l}\text { Conductor } \\
\text { insulation }\end{array}$ & $\begin{array}{l}\text { 1st turn, } \\
\text { inboard leg }\end{array}$ & 110 (comp.) & 450 (comp.) \\
\hline
\end{tabular}

2) Vacuum Vessel and In-vessel Components. HARD employs the same primary torus vacuum vessel and device cryostat concept as ITER CDA. Both thick-wall and thinwall (double skin, with internal reinforcing ribs) designs are feasible. Magnetic loading from disruptions is about $20 \%$ lower for HARD than for CDA, so the thin-wall option is more practical than it was for the CDA design.

The configuration, segmentation and internal construction of the HARD in-vessel blanket/shield modules are identical to those for CDA. The modules are subdivided toroidally into two submodules in the inboard segment and three modules in the outboard segment and can be removed through the upper vessel port by the same series of radial translations and toroidal displacements developed for the CDA modules. Clearance is $20 \mathrm{~mm}$ at the most critical point of the removal. Services for the modules exit the vessel via the upper port. Access to the remotely-maintainable service connections is slightly less restricted than for ITER CDA.

The reduced torus area of HARD relative to CDA results in a slightly reduced tritium breeding ratio (TBR). For a three-radial-zone blanket, the estimated TBR is 0.85 for HARD as compared to 0.92 for CDA. However, the lower TBR for HARD is almost exactly offset by the decreased tritium consumption and higher wall load peaking. A tritium utilization study shows that HARD and CDA will both require between 1 and $2 \mathrm{~kg} /$ year of external tritium for testing operation.

The HARD divertor plates employ the same tilebrazed-to-tube construction and segmentation as the CDA divertor plates. The plates are maintained with an in-vessel manipulator by removal and replacement through the outboard midplane ports. The reduced midplane port height for HARD requires that the divertor plate undergo an additional in-vessel rotation before it can be withdrawn.

3) Facility. The overall size of the facility (reactor building, test cell and ancillary equipment areas) required for HARD is identical to the CDA facility. Minor rearrangement of the building layout is required to accommodate the neutral beam injection configuration. The crane capacity required for assembly and maintenance must be increased to 1000 tonnes (as compared to 800 tonnes for $\mathrm{CDA}$ ) to handle the more massive HARD central solenoid.

\section{SAFETY AND RELIABILITY}

Assessment of the safety and reliability aspects of HARD shows that HARD can be, on the balance, somewhat safer and more reliable than CDA. From a safety viewpoint, the reduction in the total number of operational cycles and likely in the total number of disruptions reduces the number of accident-initiating events that weigh heavily in the overall safety evaluation. The reduced thermal and magnetic loading on in-vessel components and surfaces and overall reduction in plasma magnetic and thermal stored energies should also, other design factors being the same, reduce the chances of component failure and the severity of the consequences. HARD ignition operation will also require less tritium inventory, which will reduce the at-risk inventory for accident assessment.

These positive aspects of HARD must be balanced against the negative aspects of higher TF magnet stored energy ( $72 \mathrm{GJ}$ for HARD versus $42 \mathrm{GJ}$ for $\mathrm{CDA}$ ) and the increased activation and decay afterheat that occur in the testing phase owing to the higher wall loading.

Present safety assessments for both HARD and CDA are only semi-quantitative, since the database and methodology for quantifying the probability of fault- or accident-initiating events in a tokamak are incomplete. However, safety assessments of the ITER CDA design have focused on disruption- and/or plasma-transient initiated events as the most likely means by which inventory mobilizing scenarios can develop. The potential that HARD has for few and less severe transients thus translates into an overall modest safety advantage.

The reduced number of operational cycles and/or reduced stress levels of HARD operation can also be expected to improve HARD reliability and availability 
relative to ITER CDA. Here again the assessment is only semi-quantitative: future work on reliability assessment methods is needed for definitive quantification.

\section{R\&D REQUIREMENTS}

Research and development requirements are similar for HARD and ITER CDA. The principal difference for HARD is a need for development of higher frequency gyrotrons. Certain aspects of the R\&D are simplified: the same conductor can be used for the HARD TF and PF magnet systems, and LH launcher development is required only if the alternate current drive option is implemented.

\section{COSTS}

The total cost of HARD is estimated to be about $10 \%$ higher than for CDA (Table VII). The cost increase is mainly from the more-massive magnet systems.

\section{TABLE VII}

Cost Comparison, in $1990 \$ \times 10^{6}$ (Systems code costing, benchmarked against CDA costing)

\begin{tabular}{lll}
\hline System/Category & HARD & CDA \\
\hline Site and buildings & 488 & 509 \\
Reactor & 627 & 737 \\
Magnets & 1438 & 1056 \\
Heating/CD & 430 & 443 \\
Vacuum pumping & 59 & 52 \\
TF, PF power supplies & 183 & 135 \\
Cooling and cryogenics & 351 & 345 \\
Fuel handling & 154 & 162 \\
Plant electrical & 90 & 70 \\
Heat rejection & 32 & 42 \\
Fluid supply & 21 & 21 \\
Instrumentation and control* & 150 & 150 \\
Maintenance equipment* & 125 & 125 \\
Miscellaneous* & 25 & 25 \\
\hline Total Direct Cost & 4172 & 3834 \\
\hline Fixed cost estimate & &
\end{tabular}

*Fixed cost estimate

\section{SUMMARY}

Increasing the aspect ratio of ITER to $A=4.0$ as selected for HARD provides better balance between ignition and technology-testing performance and improves the prospects that ITER will be able to successfully complete the high-fluence nuclear-technology-testing part of the ITER Objectives. The combination of increased aspect ratio - which reduces the magnitude of current that must be sustained with non-inductive current drive, and increased on-axis toroidal field - which relaxes the constraint on plasma pressure set by the Troyon beta limit - allows HARD to achieve either true steady-state or very-long-pulse hybrid operation with the high wall loading and multi-hourduration pulse lengths needed for reactor-relevant testing.
For otherwise similar divertor conditions, HARD can achieve more than a three-fold increase in test-module neutron wall loading relative to a low-A ITER design. This improved technology testing capability is obtained without significant increase in engineering difficulty or risk, and with only modest increase in device and facility cost.

\section{CONTRIBUTORS AND AFFILIATIONS}

J. Brooks, D Ehst, Y. Gohar, and A. Hassanein, Argonne National Laboratory; J. Leuer and J. Wesley, General Atomics; S. Piet, Idaho Nuclear Engineering Laboratory; W. Cooper, Lawrence Berkeley National Laboratory; W. Barr, R. Bulmer, J. Doggett, M. Fenstermacher, S. Haney, W. Lindquist, W. Nevins, L. D. Pearlstein, L. J. Perkins, M. Rensink, S. Shen and G. Smith, Lawrence Livermore National Laboratory; K. Werley, Los Alamos National Laboratory; E. Bobrov, R. Myatt, J. Schultz and D. Sigmar, Massachusetts Institute of Technology, C. Flanagan, J. Galombos, J. Hogan, D. Lousteau, B. Nelson, N. Uckan and D. Williamson, Oak Ridge National Laboratory; S. Cohen, D. Post and R. White, Princeton Plasma Physics Laboratory; D. Ruzic, University of Illinois.

\section{ACKNOWLEDGEMENTS}

The activities of the U.S. ITER Team are supported by the U. S. Office of Fusion Energy. The author's work and preparation of this paper are supported by Lawrence Livermore National Laboratory Subcontract No. B089350.

\section{REFERENCES}

1. "Establishment of ITER: Relevant Documents," IAEA/ITER/DS/1, IAEA (1988)

2. "ITER Conceptual Design Reporn," IAEA/ITER/DS/18, IAEA (1991)

3. "ITER Tokamak Device," IAEA/ITER/DS/25, IAEA, (1991)

4. "ITER Parametric Analysis and Operational Performance," LAEA/ITER/DS/22, LAEA (1991)

5. "ITER Physics," IAEA/ITER/DS/22, IAEA (1991)

6. "ITER Magnets," IAEA/ITER/DS/26, IAEA (1991)

7. "ITER Operations and Research Program," IAEA/TTER/DS/23, IAEA (1991)

8. "ITER Poloidal Field System," IAEA/ITER/DS/27, IAEA (1991)

9. L. D. PEARLSTEIN, S. W. HANEY and J. P. FREIDBERG, "A Variational Procedure for Vertical Stability," Bull. Amer. Phys. Soc. 35, 2117 (1990)

10. "ITER Safety," IAEA/ITER/DS/36, IAEA (1991)

11. "ITER Current Drive and Heating System," IAEA/ITER/DS/32, IAEA (1991) 